\title{
The multimodal enactment of deontic and epistemic authority in Indian meetings
}

\author{
Jonathan Clifton, Dorien Van De Mieroop, Prachee Sehgal \\ and Dr. Aneet \\ University of Valenciennes / KU Leuven / I.K.G. Punjab Technical \\ University, Jalandhar
}

Authority is a much discussed topic in organizational literature, but its in situ enactment is little investigated. Using the notions of deontic and epistemic authority and using multimodal conversation analysis as a research methodology, the purpose of this paper is to provide an empirical study of authority-in-action. We particularly focus on both sequences of talk and the multimodal resources that are mobilised to 'do' authority. Furthermore, as research from non-Western contexts remains rare, we complement insights into authority enactment based on 'Western' data by using data that is drawn from a corpus of naturally-occurring video-recorded faculty meetings at an Indian University. Findings indicate that the doing of authority can be made visible by explicating participants' orientation to their respective deontic and epistemic rights and their invocation of particular identities, which are accomplished by means of a complex intertwining of verbal and non-verbal resources.

Keywords: authority, deontics, epistemics, conversation analysis, meetings, India, multimodality

\section{Introduction}

Authority is, as Taylor and Van Every (2014, xx) claim, "the foundation of organization because without it there would be no unifying force". However, despite this centrality of authority, there has been little investigation of how it is enacted in organisations. Furthermore, even less (if any) research has focused on the multimodal accomplishment of authority, and little (if any) has used data from non-Western contexts. Using multimodal conversation analysis (CA) as a methodology and linking this to recent work on epistemic and deontic authority, the purpose of this paper is to address these lacunae (1) by making visible, and thus analysable, both 
the sequences of talk and multimodal resources with which authority is achieved and (2) by using data that comes from a relatively under-researched context, at least as regards CA - viz. faculty meetings in India -, we provide a more globally based analysis of the in situ accomplishment of authority. Findings indicate that both the sequential and the multimodal features of the interaction are recipient-designed to make relevant particular institutional identities. The relevance of these identities for the interaction reflexively makes visible members' orientations to each other's relative deontic and epistemic rights, thus performing the authority of the participants vis-à-vis each other which is linked to certain identities within the organisation's hierarchy.

\section{Authority}

Traditionally, authority is differentiated from power and influence (Lukes 1978). Power (Macht), classically defined by Weber $(1978,53)$ as "the probability that one actor within a social relationship will be in a position to carry out his own will despite resistance, regardless of the basis on which this probability rests", can be coercive, illegitimate, or based on brute force. Whereas authority (Herrschaft) is defined by Weber $(1978,53)$ as "legitimate power" which is based on the belief of both the dominant and the dominated in the rightness of the exertion of power. The crucial difference between power and authority thus being that authority is seen as the legitimate exercise of power. Following Weber $(1978,215)$, authority has three pure types: traditional; charismatic; and rational-legal. This paper focuses on the rational-legal type, which Weber $(1978,215)$ defines as "a belief in the legality of patterns of normative rules and the right of those elevated to authority under such rules to issue commands". Essential to the notion of authority therefore is that one gives up one's own private judgement in deference to somebody who, or something that, is oriented to as having authority.

Within an organizational context, authority used to be regarded as being strongly embedded in a chain of command in which managers had both knowledge of what needed doing and legitimate status, inherent in their position, that gave them the right to tell their subordinates what to do and how to do it (see e.g. Taylor 1911). However, this form of vertical authority is increasingly being challenged. This, it is argued, is because since the 1980s and the arrival of the so-called New Work Order (Gee, Hull \& Lankshear 1996), organizations have become increasingly characterized by seemingly flattened hierarchies which have made the linear and explicit exercise of authority disappear. Yet, in order to ensure stability, authority remains essential to organisations. In other words, as Taylor $(2009,230)$ notes, the role of authority is "to bind co-orientational relationships to each other sufficiently 
to hold the delicate fabric of human relationships together". However, as research is largely based on western contexts, it remains to be seen whether this flattening of hierarchies in New Work Order organisations can be considered a global phenomenon (see discussion in the 'data' section).

Importantly, despite extensive research into authority in organisational settings cited above, Kahn and Kram (1994) argue that: (1) most research into authority has been either experimental or based on psychometric measures and (2) little research has been carried out into the in situ doing of authority (see also Taylor \& Van Every 2014, xviii). Consequently, it is claimed that "researchers know little [else] directly about authorizing and de-authorizing processes in work organisations" (Kahn \& Kram 1994, 19). Using multimodal CA, and building on recent CA work on epistemic and deontic authority, we therefore intend to provide an explication of the accomplishment of authority as an in situ member's accomplishment.

\section{Method - multimodal conversation analysis and authority}

Within CA, there is a growing interest in two important and interrelated concepts that are related to authority: viz. epistemics (e.g., Raymond \& Heritage 2006; Heritage 2012) and deontics (e.g., Stevanovic \& Peräkylä 2012; Stevanovic 2015). Epistemic authority is, as Stevanovic and Peräkylä $(2012,297)$ point out, the right to know how the world is. Yet, as various researchers have argued, the right to know "how the world is" is not something that participants 'have', rather it is negotiated in interaction and may, or may not, relate to actual states of knowledge (Drew 1991). For example, in the case of news anchors and local reporters, Raymond (2000, 365) argues that it is the participants' orientation to the social position, or "role-based identity", rather than the actual state of knowledge of the local reporter which allows him/her to claim epistemic authority. Consequently, as Heritage $(2013,371)$ argues "since personal and social identities are also formed from what persons have experienced and lay claim to have access to and to know, the epistemic claims that are enacted in turns-at-talk are central to the maintenance of identity itself". Moreover, who has rights to claim and display knowledge is negotiated through the sequential properties of talk (see Heritage (2013) for a summary of these) in which participants' epistemic statuses and stances are negotiated. Following Heritage $(2012,6)$, epistemic status relates to the enduring features of a social relationship and stance relates to the "moment by moment expression of that relationship, as managed through the design of turns at talk". Returning to the definition of authority as giving up one's own private judgement in deference to somebody who, or something that, is oriented to as having authority, the analysis of the sequential resources by which participants negotiate their relative epistemic stance and status thus allows 
the researcher to make visible, and thus analysable, the doing of authority as in situ social action. More specifically, when related to rational-legal authority, through analysing the negotiation of epistemic rights and who defers to whose knowledge claims, a researcher can make visible how participants use their role-based institutional identities as discursive resources for managing epistemic rights through which authority is achieved.

A second source of authority is deontic, which concerns rights to determine the future actions of others (Stevanovic \& Peräkylä 2012, 297). These rights can be proximal if related to local sequences of interaction, or distal if related to future doings (Stevanovic 2015). Deontic rights, as with epistemic rights, are negotiated in interaction and authority-in-action can be made visible in the way in which participants challenge or acquiesce to the deontic rights of others. Moreover, in the case of legal-rational authority which is related to oriented-to institutional identities that become procedurally relevant to the interaction, deontic rights are displayed both in participants' displays of status and stance. Deontic status denotes "the relative position of authority or power that a participant is considered to have or have not, irrespective of what he or she publically claims" and deontic stance "refers to the participants' public ways of displaying how authoritative or powerful they are in certain domains of action relative to their co-participants (Stevanovic \& Svennevig 2015, 2).

Essential to the interactional achievement of epistemic/deontic stance and status which underlies the doing of authority is the notion of recipient-design whereby the action, or actions, that a turn at talk perform(s) make(s) relevant a particular identity of both the recipient and, reciprocally, the speaker (Sacks, Schegloff, \& Jefferson 1974, 727). In the case of legal-rational authority, we are thus particularly concerned with how one's institutional role-based identity (cf. Raymond 2000) is oriented to by participants and made relevant to the interaction. So, for example, in order to avoid sanction, participants design their talk so that it is appropriate for the situation and congruent with their relevant institutional identities. Through such an orientation to what constitutes "allowable contributions to talk" (Levinson 1992) for certain identities, the participants orient to who they are in relation to whom, thus talking into being their, and others', identities. Participants thus simultaneously use social order as a resource for carrying out their activities and enacting that social order. Finally, and self-evidently, the notion of rational-legal authority - which is based on one's position within an organisation - is essential to this social order. This is because it implies members' orientation to who has the legitimate right to tell somebody what to do and what to think. The invocation of the participants' (hierarchically positioned) organisational identities thus lies at the heart of any discussion of legal-rational authority. 
In this paper, we focus specifically on the role of the chair in meetings and how his/her authority is enacted. As Sacks, Schegloff, and Jefferson $(1974,729)$ pointed out, meetings are events in which turn taking deviates from conversation. This is because meeting-talk is often mediated by a chairperson who, as Asmu $\beta$ and Svennevig $(2009,11)$ note, is given the "institutional authority to moderate the talk". Therefore, such activities as opening and closing the meeting, introducing topics on the agenda, facilitating and closing down topic-talk, introducing the next item on the agenda, allocating turns at talk, selecting the next speaker, and sanctioning inappropriate conduct constitute relatively stable deontic asymmetries which are bound to institutional roles (Stevanovic \& Peräkylä 2014). Significantly, the role of the chair in a meeting is often associated with the hierarchical position in the organisation and is often allocated to the highest ranking participant (Angouri \& Marra 2010). Potentially, at least, it is thus a combination of being the chair and being the hierarchic superior that gives the chair the institutional authority to moderate talk.

Even though there has been some previous CA-research on the role of the chair (e.g. Larrue \& Trognon 1993; Pomerantz \& Denvir 2007), little of this research has dealt with the multimodality of the chair's function (though see Barske 2009). In adopting a multimodal approach, we not only endeavour to analyse authority in interaction as it is talked into being, but also as it is achieved through a variety of other non-verbal practices. This implies that we follow recent calls to overcome a purely logo-centric vision of communication (Mondada 2016), and that explications of the actions being performed are complemented with analyses of the participants' use of resources such as gesture, gaze, head movements, facial expressions, body posture, body movements, and embodied manipulations of material objects (see, for example, Goodwin $(1981 ; 2000)$ and Heath and Luff (2013), as well as the spatial configurations in which these occur (e.g. Deppermann, Schmitt \& Mondada 2010). It is important to emphasize that we will not focus systematically on one specific non-verbal resource (such as eye gaze), but that we adopt an integrative conception of multimodality (Mondada 2016, 360), which is in line with recent CA-trends. To date, CA-inspired research has not specifically combined multimodal investigation with sequential analyses of talk to consider how authority is achieved (though for a study on the multimodal display of authoritative and subordinate status in girls' pretend play, see Griswold 2007). Therefore, as noted previously, the purpose of this paper is to draw on the concepts of deontic and epistemic authority and the way in which participants in a meeting recipient-design their turns, so making procedurally relevant identities that entail certain epistemic and deontic rights with which legal-rational authority is achieved. One of the novelties of this paper thus lies in the fact that we widen our analytic scope and to take into account nonverbal resources that achieve authority. 


\section{Data}

Another novelty of this paper is that we focus on a traditionally under-researched context. Prior work on authority has tended to use as data from Western organizational contexts which are characterized by seemingly horizontal hierarchies (Van De Mieroop \& Clifton 2017). However, these processes may not be entirely similar across the globe. Yet, to date, even though insights can be gained from widening the research lens, research on non-Western contexts is largely lacking (though see some contributions in Van De Mieroop and Schnurr 2017). In this article, we aim to contribute to widening this lens by focussing on data collected in India.

Indian social systems are generally regarded as "steeply hierarchical" and Indians as highly "status conscious" (Sinha \& Sinha 1990, 708). In particular, Indian organizational culture is said to be characterized by a general orientation to vertical hierarchies. The typical Indian employee tends to align with their superiors' opinions (Sinha \& Sinha 1990) and "respects people in power, is obedient, submissive, and law-abiding" (Varma, Ekkirala \& Stroh 2005, 86). This significantly influences leader-subordinate relationships in India, which can be characterized as inspired by a "parental ideology" (Kakar 1971). However, in India, there are signs that this situation is starting to change, and it has been observed that there is increasing pressure on leaders in Indian corporations to adopt an "empowering control style", which is intended to enhance the organizational commitment of the employees (Bhatnagar 2005). However, despite these gradual changes, it is still safe to conclude that in comparison to their Western counterparts, 'cultural' expectations concerning Indian organizations point to a stronger orientation to hierarchical differences and vertical authority. But, as many researchers have pointed out (see e.g. Verschueren 2008), it remains to be seen whether these generalizations are corroborated by actual organizational practices, which we aim to scrutinize here.

In particular, the data comes from an anonymized corpus of video-recorded faculty meetings that were filmed in 2015-2016 in a private university in a large city in the north of India. All the data were transcribed using the Jeffersonian transcription system (Jefferson 2004), which we complemented with symbols to code the multimodal details as developed by Mondada (n.d.) (see Appendix 1). The faculty meetings are held once a month and the objective of the meetings is to update the faculty, department heads and the director on events on campus and also to plan any special events that might be forthcoming. No formal agenda is provided prior to the meeting and no formal minutes are circulated after the meeting.

The particular extracts presented here come from one faculty meeting during which 17 faculty members were present including the department head (given the pseudonym Ryan) and the director of the institute (given the pseudonym Amit). The faculty members are seated in a horseshoe formation with the director in a 
central position and the department head on his left (see Appendix 2). Written consent and authorization to film was obtained from the participants and from the relevant university ethics committees.

\section{Analyses}

In the part of the meeting analysed in this paper, student club activities are being discussed. This takes the form of doing a round of reports (Svennevig 2012) in which faculty members responsible for clubs present the activities of their clubs. These activities are then discussed, the reports are assessed and suggestions are made for future action. In all, the activities of seven clubs were presented of which, for reasons of space, only three are presented here. The presentation of the clubs all followed a similar sequence in which the chairperson initiates topic shift to a club's activities and the faculty member responsible for the club subsequently reports on the club's activities. These activities are assessed, action if needed is suggested, and the chair then closes the topic and selects the next speaker. These sequences thus provide an ideal terrain in which epistemic and deontic rights are negotiated. Through these processes, authority based on members' orientation to each other's institutional roles is made visible.

\subsection{Extract one: The IT club}

First we present a sequence in which the director of the institute, acting as chair, allocates topic and turn, after which the faculty member responsible for the IT club provides a report of the club's activities and the chair/director then assesses this and closes topic.

Extract 1. The IT club ${ }^{1}$

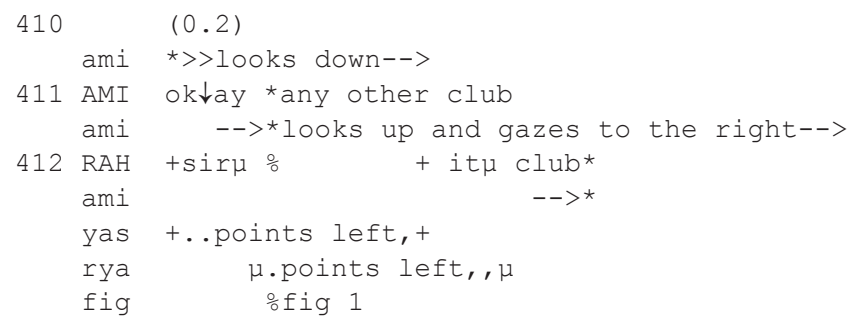

1. Given our analytical focus, we transcribed the chairperson's eye gaze throughout the extracts. Whist recognising that this has analytical implications for the discussion, we weighed such possible bias against making the transcript too 'heavy', and we decided not to include codings of the others' eye gaze in the transcript. Yet, whenever relevant, we show the others' gaze via the figures containing screenshots of the interaction. 
340 Jonathan Clifton, Dorien Van De Mieroop, Prachee Sehgal and Dr. Aneet
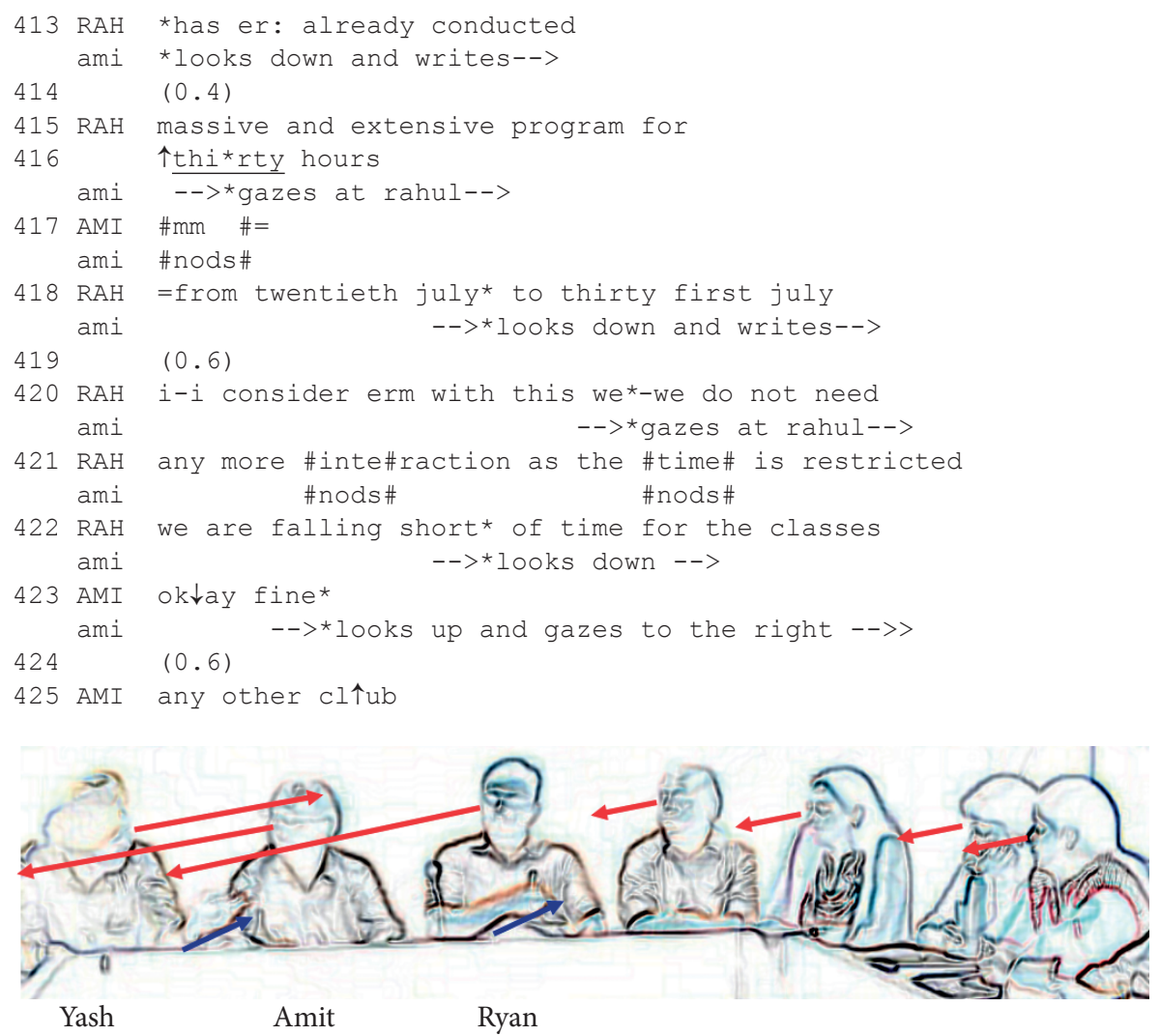

Figure 1. Yash pointing and gazing left, while Amit is gazing right and Ryan is gazing right but pointing left. Four remaining participants to the left of Ryan all gaze to the right. Other people (e.g. Rahul) are outside of the camera's angle at this point in the interaction. $^{2}$

In line 410 , there is a slight pause after closure of the prior topic. In line 411, Amit, the director of the institute, self-selects to close down the prior talk using ok $\downarrow$ ay combined with averted eye gaze (Barske 2009) and, by looking up, introduces a slot for the discussion. In this case, he looks right, as such selecting someone on his right as next speaker via eye gaze. Rahul, sitting on Amit's right, responds to this by providing a conditionally relevant second action, i.e. he starts to report on the IT club. Interestingly, both Ryan and Yash, through gesturing left, display a right to co-author turn allocation (see Figure 1). However, nobody on their left takes the next turn, even though there are four participants seated in this area who all gaze in

2. In all the figures, relevant gazes are indicated by red arrows, while gestures are marked by blue arrows or circles. 
the direction of Yash, Amit, and Ryan and thus can see the gestures (see Figure 1). Thus, only Amit's next speaker nomination through his eye gaze is aligned with, and this makes relevant his identity as turn manager and as 'chairperson'. Meanwhile, Yash and Ryan's co-authoring turn allocation ${ }^{3}$ is not ratified, even though this is within the range of Rahul's eye gaze, as the three potential turn allocators (Yash, Amit, and Ryan) are seated next to one another (see Figure 1). Consequently, Rahul produces a turn which is congruent with Amit's (and not Yash and Ryan's) proximal deontic claim to manage turn taking by nominating next speaker and topic. Moreover, since Rahul recipient-designs his turn confirming Amit's claim to manage turns, this makes relevant the latter's institutional identity as chairperson who has legitimate authority to manage turns at talk during the meeting.

In his answer, Rahul explicitly nominates Amit as his addressee (line 142: sir) and he provides a conditionally relevant next action (i.e. an account of the IT club's activities) which is congruent with Amit's proximal deontic claim to nominate the next speaker and topic and to be informed about the club's activities. Rahul is therefore attributed $\mathrm{K}+$ status and the recipient of the talk (i.e. Amit) K- status. Thus, Rahul's authority for knowing about the club is based on the relevance of his identity as faculty member in charge of the club and his $\mathrm{K}+$ status - made relevant by the fact that the turn is addressed to him. Rahul's turn consists first of a report of the club activities (lines $412 \mathrm{ff.}$.: IT club has er: already conducted (0.4) massive and extensive program for $\uparrow$ thirty hours from twentieth July to thirty first July). Significantly, the subject of the utterance is the IT club, not Rahul, so Rahul makes relevant his position of faculty member in charge of the IT club to speak on its behalf and thus with the authority of the club. He then assesses this state of affairs (lines $420 \mathrm{ff}$. I-I consider erm with this we we do not need any more interaction) and this is followed by an account for the assessment (lines $421 \mathrm{ff} .:$ as the time is restricted we are falling short of time for the classes). Thus, through proffering an account, his assessment is slightly downgraded which also displays a diluted authoritative stance.

As Rahul's turn is in progress, Amit nods (parallel with line 421) which, as Stivers (2008) argues, displays tacit agreement with the turn in progress. When the turn is finished, Amit then takes the floor. Prefacing his turn with an acknowledgement token ok $\downarrow$ ay, he then produces a conditionally relevant next action which is to provide a second evaluation (Pomerantz 1984) and so he evaluates the prior talk (line 423: fine). The assessment takes the form of an unmarked declarative and as such displays equal, rather than superior, rights to assess the club's activities (Raymond \& Heritage 2006, 690). This stance thus makes relevant his epistemic

3. It is important to note that Ryan's turn allocation is ambiguous: as he gazes right, thus parallel with Amit's gaze, he is also pointing in the opposite direction. 
status (i.e., right to know about how to manage clubs) but it does not display superior rights to assess the activities of the club. Thus, symmetric epistemic rights are displayed between the faculty member who runs the club and the boss who is informed about the running of the club.

There is then a micro pause after which Amit initiates a topic shift (line 425: any other $\mathrm{cl} \uparrow \mathrm{ub}$ ) while still gazing to the right, thus opening up the floor to other faculty members again.

\subsection{Extract two: The sports club}

In this section, we discuss an extract in which the chair displays deontic rights to allocate turns and topic, but in which a faculty member who is not in charge of the club suggests further action and evaluates the report of the club's activities. This faculty member thus claims deontic and epistemic primacy in relation to a club for which she is not responsible.

Extract 2. The sports club

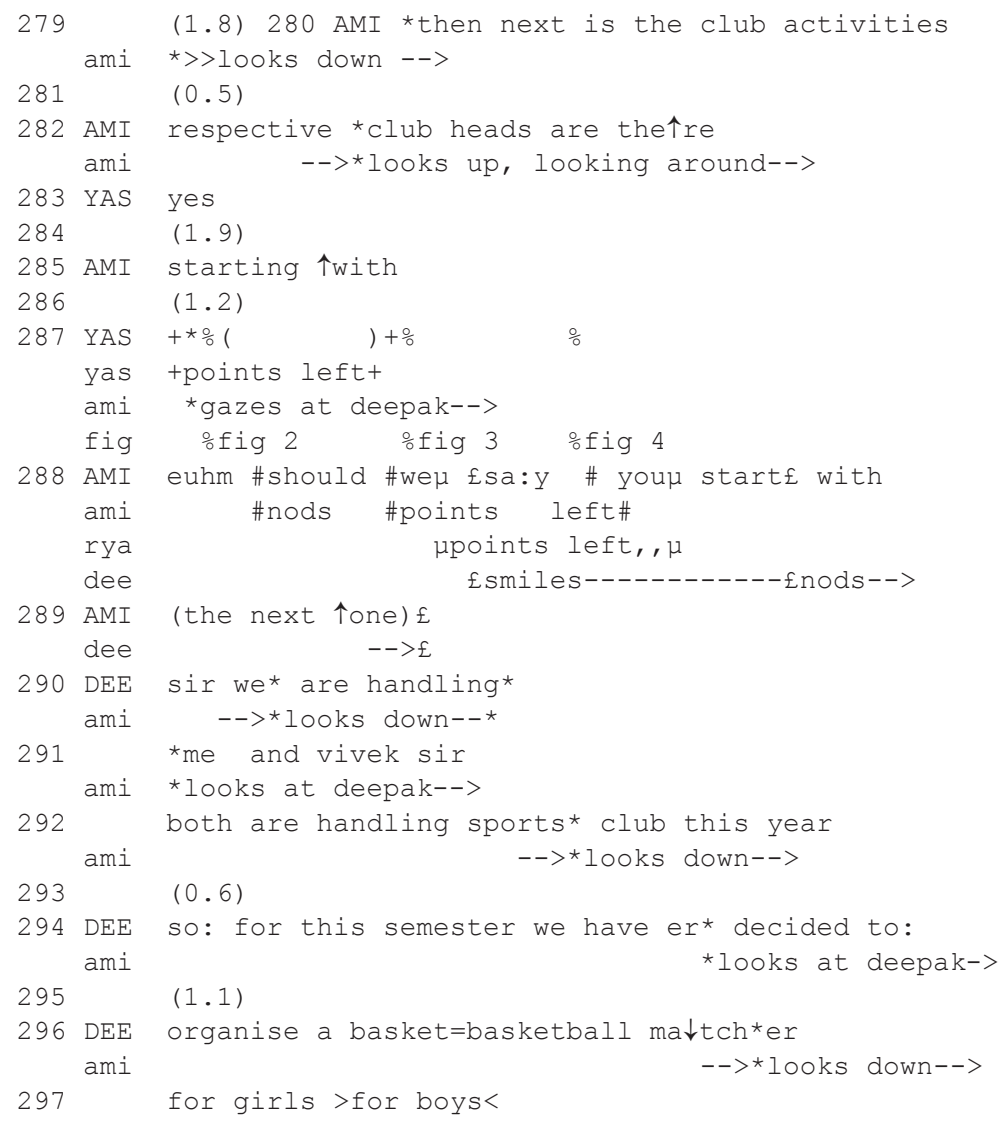



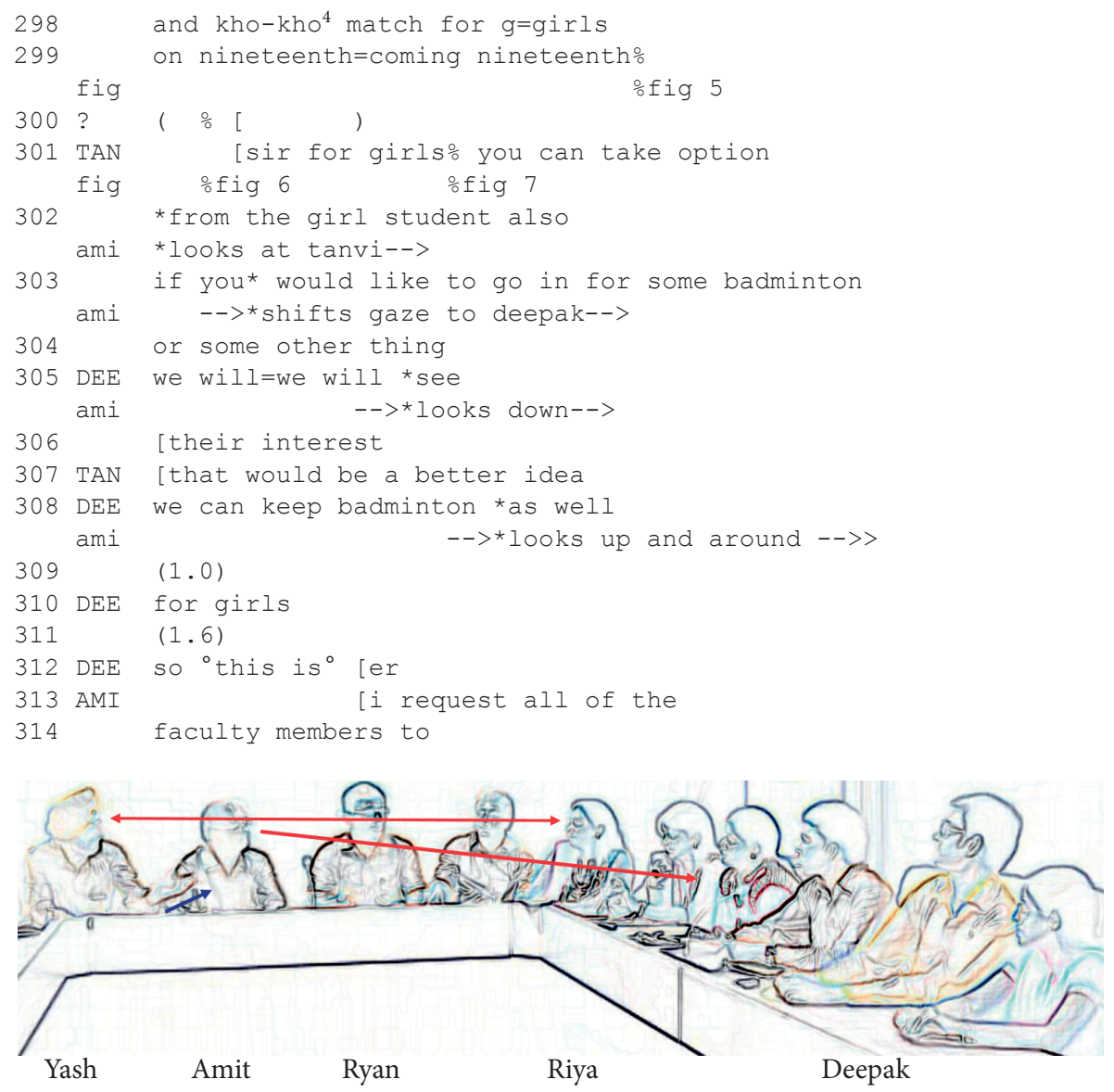

Figure 2. Yash points and gazes at Riya with a sharp angled look left, while Amit gazes left with a wide angle in the direction of Deepak

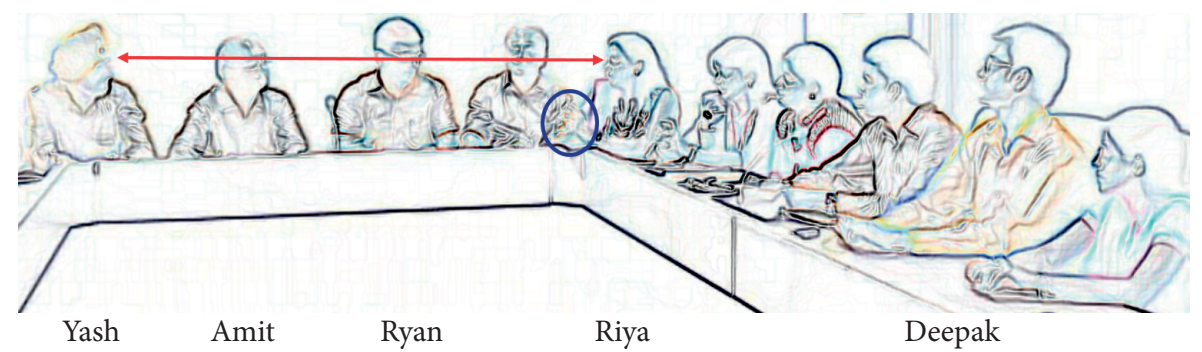

Figure 3. While there is mutual eye gaze between Yash and Riya, Riya moves the palm of her hand up

4. Kho-Kho is a tag sport that is played in teams. Both girls and boys play it, yet hardly ever in mixed teams. 


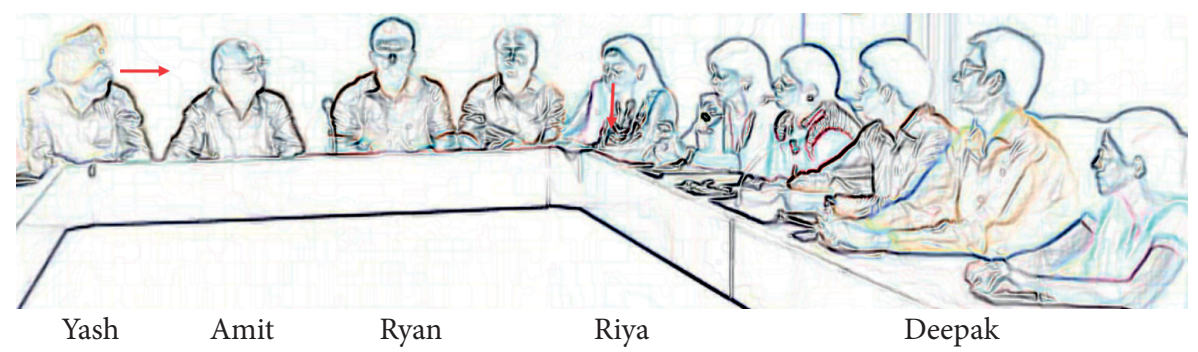

Figure 4. While Yash is still gazing in the direction of Riya, the latter looks down

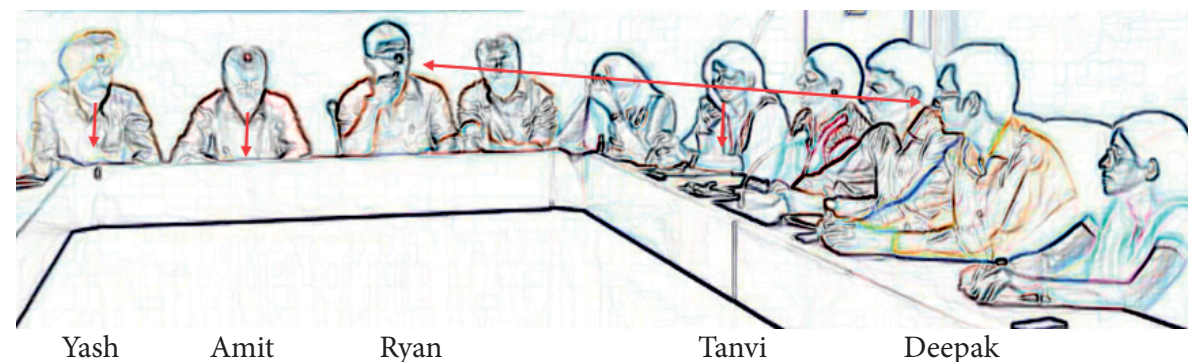

Figure 5. Yash, Amit and Tanvi are looking down while Deepak is gazing at Ryan, who reciprocates his gaze

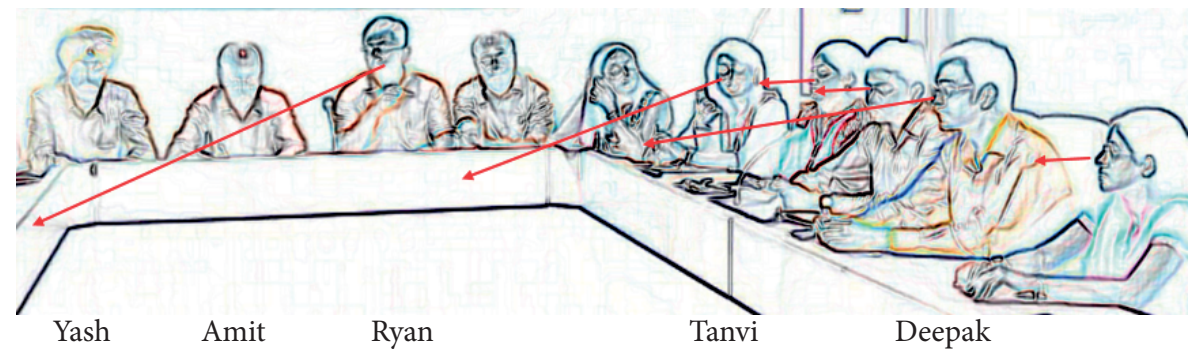

Figure 6. Someone across the table takes the turn (outside of the camera's angle at this point) and Ryan, Tanvi and Deepak gaze at this speaker, as well as some of the other participants

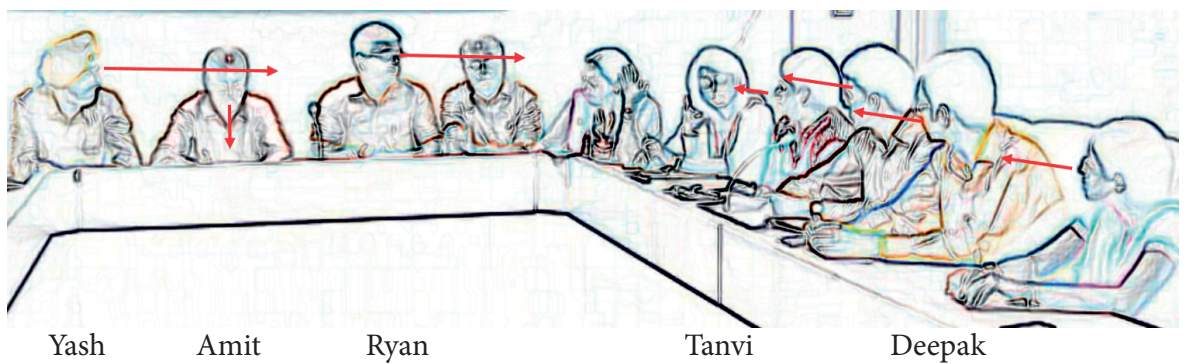

Figure 7. Most participants gaze at Tanvi while she is speaking, except for Amit, who is still looking down 
Following a pause, Amit announces the next item to be dealt with (i.e., club activities) thus claiming the deontic right to select topic. After a further pause, Amit begins to seek the next speaker (line 285: starting $\uparrow$ with) thus claiming proximal deontic rights to select next speaker. After a further second pause, Yash utters an unintelligible turn and points left, as such attempting to co-author the selection of the next speaker and also therefore claiming deontic rights to manage turn taking. He gazes left with a sharp angle (see Figure 2) in the direction of Riya, who reciprocates his gaze, but who then almost immediately makes a hand gesture moving her palm up in the direction of Yash (see Figure 3). After this movement, she looks down (see Figure 4), thus displaying her unavailability to take the turn. As such, through gesture and eye gaze, she non-verbally declines Yash's selection of her as the next speaker. Meanwhile, Amit also gazes left (see Figures 2 to 4), but with a wide angle, thus looking in the direction of Deepak. He subsequently explicitly selects Deepak as next speaker (line 288: euhm should we sa:y you start with the next $\uparrow$ one). This move is mirrored by Ryan, who also points left, and so co-authors the turn and claims deontic authority to manage the turn taking. However, since Amit's pointing is already in motion, this turn follows Amit, and therefore makes limited claims to superior rights to allocate turns. So we can observe here that Yash's speaker selection is again unsuccessful and Amit enacts his identity as turn manager with proximal deontic rights to select the next speaker. Thus, whilst rights to manage turns are claimed by Amit which makes relevant his role based identity of chair which gives him the authority to do this, it is also negotiated in subtle ways, for example by Yash and Ryan's gesturing which attempts to co-author turn management and so claims rights to manage turns. These attempts are largely ignored by Amit and by the other faculty members - or even declined, as was the case with Riya - and so the meeting participants clearly orient to Amit's authority as the turn manager.

In lines 290 ff., addressing Amit (line 290: sir), Deepak produces a turn that is congruent with Amit's claims to manage turn-taking. Deepak reports that he and Vivek are handling the sports club. This makes relevant his institutional position as faculty member responsible for the club and thus provides his source of authority for reporting on its activities and having a $\mathrm{K}+$ status. Since he is selected to report on the club, his $\mathrm{K}+$ status is made relevant and he recipient-designs his turn for Amit who has K- status and therefore needs to be informed. This, therefore, also makes relevant Amit's status as boss who has the right to know what is happening in the club. After making relevant his identity which gives him epistemic authority, he formulates a report of the club's activities. In the report, he claims deontic rights to decide future action (lines $294 \mathrm{ff}$.: we have decided er decided to: (1.1) organise a basket=basketball ma $\downarrow$ tch er for girls $>$ for boys $<$ and kho-kho match for $\mathrm{g}=$ girls on nineteenth=coming nineteenth). After Deepak's report of the sports club's activities and claim to epistemic and deontic rights to know and decide what to do 
(lines 290-299), most people are looking down (see Figure 5) and, importantly, Amit as the chairperson, is one of them. As such, there is no verbal or non-verbal next speaker selection at this point. Then someone on the other side of the table (outside camera angle) self-selects to take the next turn (line 300). While many participants orient their gaze to this speaker (see Figure 6), Tanvi self-selects to overlap this speaker after the turn's beginning (line 301). Soon after this overlapping talk, most participants orient their gaze towards her and as such she successfully obtains the floor (see Figure 7).

In line 301, Tanvi prefacing her turn with 'sir', claims the deontic right to suggest future action to Deepak who is confirmed as recipient through her shift in eye gaze (which we can also observe in Figure 7). The suggestion is that, "for girls you can take option from the girl student also if you would like to go in for some badminton or some other thing" (lines 301-304) therefore hinting that Deepak's management of the club is somehow problematic and needs remedial action. More specifically, through the use of the modal 'can', indicating possibility rather than certainty, and the conditional form ('if you would like'), her turn is designed as a suggestion which is contingent upon Deepak's agreement and it thus has a very shallow deontic gradient (Landmark et al. 2015, 56). However, Deepak only partially aligns with this suggestion and claims the right to make a decision that is contingent on the interest of the girls (lines 305-306: we will=we will see their interest). Interestingly, he uses an ambiguous 'we'-form which could refer to himself and Vivek, or himself, Vivek, and the club. Either way, he claims to speak on behalf of the club and so provides a source of authority for his deontic right not to defer to Tanvi's suggestion but to postpone taking action until they have seen the girls' interest in badminton. He therefore mobilises the authority of the club members as a resource for not surrendering his own private judgement to align with Tanvi's suggestion. Consequently, he resists Tanvi's distal deontic claim and displays a stance that Tanvi does not have superior deontic rights in relation to the sports club which he and Vivek (line 291) are handling.

Tanvi again self-selects and overlaps this turn as it is in progress with an assessment of the deontic claim to postpone the decision (line 307: that would be a better idea). On the one hand, this assessment is slightly downgraded through the use of the conditional form (would) but at the same time this downgrade is mitigated by the fact that she offers no account for her assessment and so presents it as a declarative which displays her epistemic rights to assess the prior speaker. Thus, by suggesting that Deepak is right, she claims a right to judge his assessment and so claims superior expertise. However, she offers no authority for this and her identity as faculty member makes relevant no particular epistemic or deontic rights in respect of the sports club. Despite the lack of an identity that could make superior epistemic or deontic rights relevant, Deepak produces a turn which aligns with Tanvi's suggestion to offer badminton for the girls (lines 308-310: we can keep 
badminton as well for the girls). However, the use of the modal 'can', indicating future possibility, mediates his alignment with Tanvi's deontic stance and so he produces a turn that is not fully congruent with Tanvi's suggestion to offer badminton for the girls. Therefore, whilst conceding that offering badminton is a possibility (contingent on the girls), he does not fully comply with Tanvi's suggestion and so retains his deontic right to manage his club's future activities. Thus, in the exchange between Tanvi and Deepak, fellow faculty members negotiate who has deontic rights to tell whom to do what. However, the relevance of Deepak's institutional role as faculty member in charge of the club allows him to mobilise the authority of the club to resist Tanvi's deontic and epistemic claims in relation to the club.

The negotiation of epistemic and deontic rights in relation to the sports club is cut short as Amit overlaps to change topic to a request to faculty members to ensure that they inform the heads of departments when planning club activities. ${ }^{5}$ As such, Amit closes the presentation and evaluation of the club's activities without having taken part in the negotiation of epistemic and deontic rights himself.

\subsection{Extract three: The finance club}

In this final extract we demonstrate how the chair's deontic and epistemic rights can be resisted.

Extract 3. The finance club

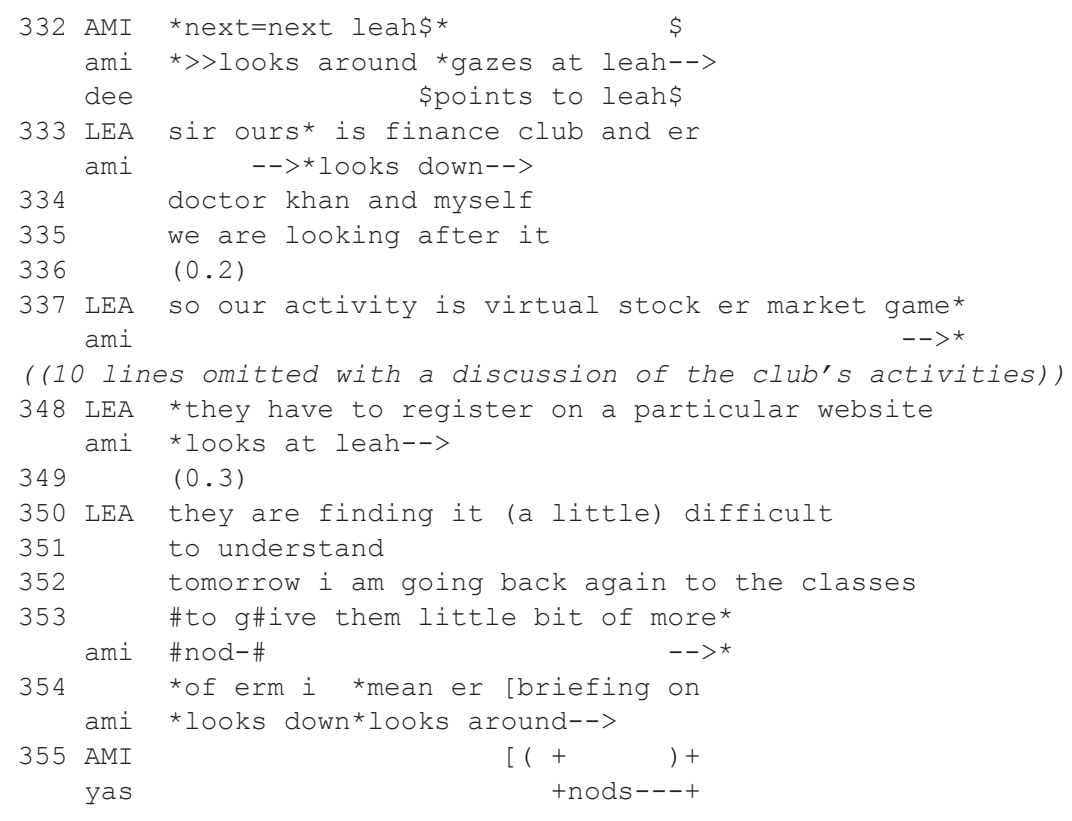

5. This turn is not fully shown here for reasons of space. 

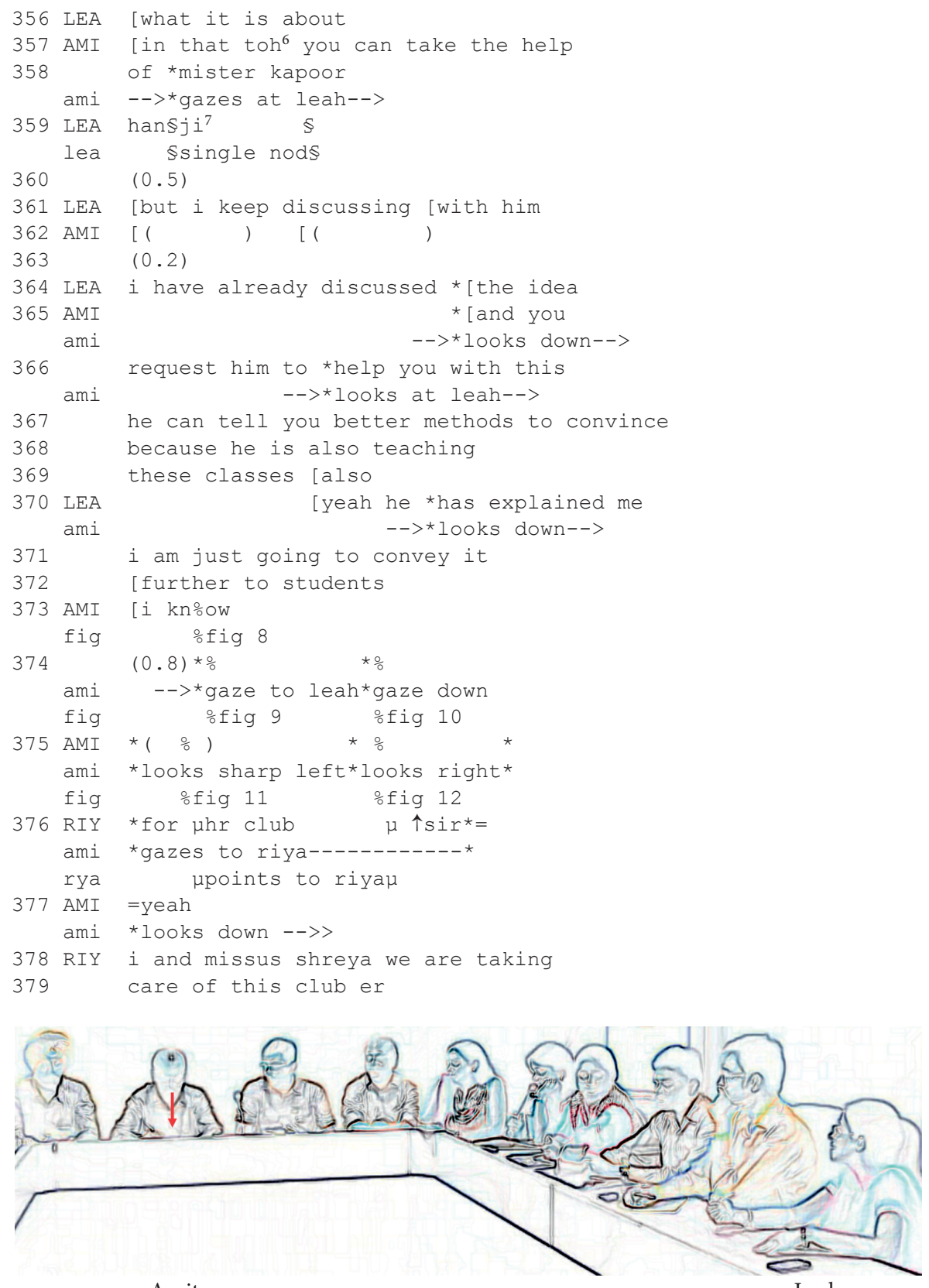

Amit

Leah

Figure 8. Amit looking down while uttering 'I know'

6. Hindi: so

7. Hindi: yes $($ han $)+$ honorific marker $(-j i)$ 


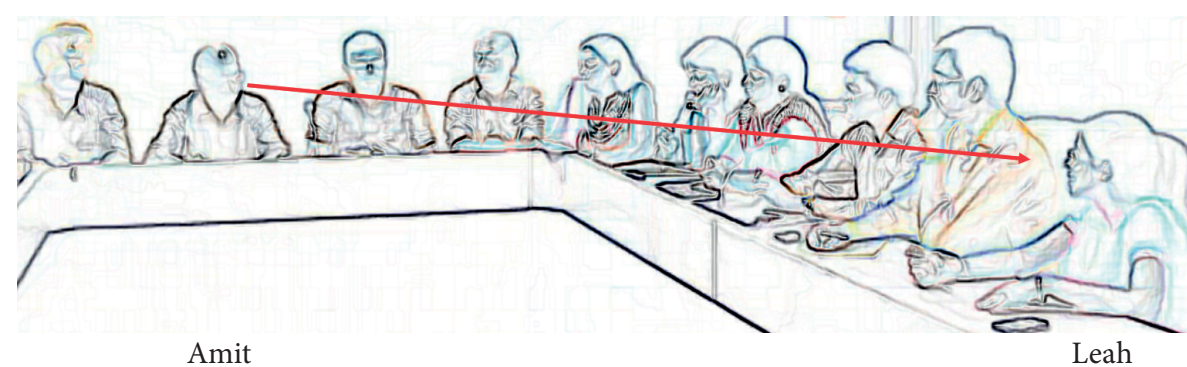

Figure 9. Amit executes a quick gaze shift with a micro look at Leah

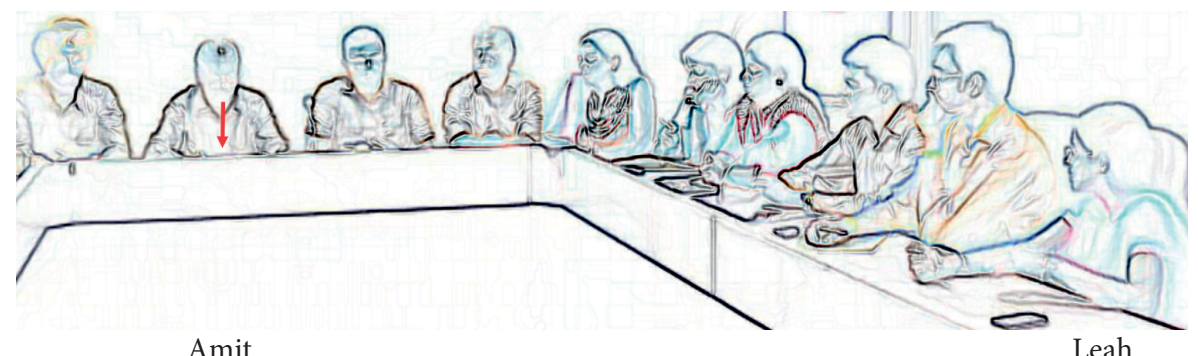

Figure 10. Amit shifts his gaze back to his paper

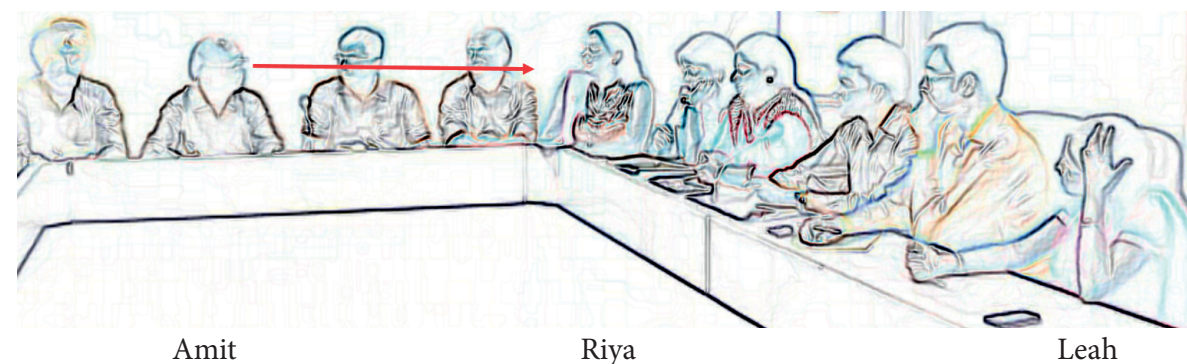

Figure 11. Amit looks left with a sharp angle

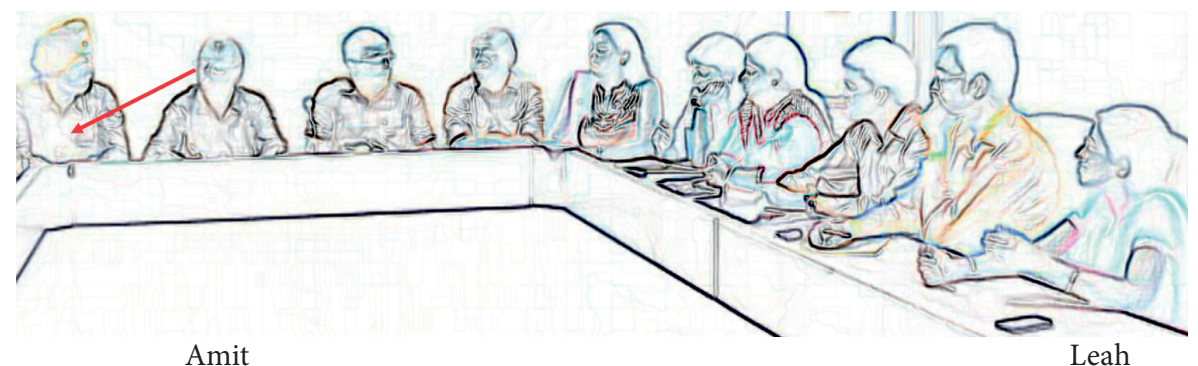

Figure 12. Amit looks right with a wide angle 
As in the prior extracts, after being nominated by Amit, Leah reports on the finance club. In line 333, she announces that "doctor Khan and myself we are looking after it", thus establishing the relevance of her identity of faculty member in charge of the finance club. Using 'so' to formulate a report of the activities, she details these activities (lines 337-346, not fully shown here for reasons of space). She then (cf. Extract (1)) assesses these activities (line 350: they [the students] are finding it a little difficult to understand). This is done in an unmarked declarative, thus claiming unmediated access to the assessable, and thus displaying her epistemic rights to assess (Raymond \& Heritage 2006, 686). She then discloses the remedial action she intends to take, thus claiming distal deontic independence and rights to decide on actions relating to the club (line $352 \mathrm{ff}$.).

While this turn is in progress, Amit nods (line 353) which displays acknowledgement of, and tacit agreement with, the turn in progress (Stivers 2008). However, in line 357, Amit overlaps this turn in progress and formulates a suggested next action: "you can take the help of mister Kapoor". Using the modal 'can', he uses a shallow deontic gradient and presents this as conditional on Leah's agreement rather than as a direct command (e.g. you must). But despite this shallow gradient, he nevertheless asserts his deontic rights to direct Leah's activity and so reflexively he constructs his deontic authority in the matter of running clubs. However, this deontic claim is met with resistance and a dispreferred second (Pomerantz 1984) which takes a classic dispreferred turn shape of token agreement (hanji ('yes') and nod) followed by disagreement, signalled with a contrastive 'but'. Interestingly, for this token agreement, Leah briefly switches to Hindi, using the affirmative particle han and the enclitic honorific -ji, thus at the same time making relevant Amit's hierarchically higher status as director of the institute. Yet, as mentioned, Leah continues with a dispreferred turn (line 361), in which she claims that she "keeps discussing" with Mr Kapoor and that they "have already discussed the idea" (line 364). This makes relevant her first-hand knowledge of what is going on. It is also an assertion of her epistemic primacy (Raymond and Heritage 2006, 684) in this matter, and it rejects Amit's suggestion to "take the help of mister Kapoor" (line 357) since she has already done so. Amit overlaps at two points as Leah's turn is in progress, but his words are unintelligible. Finally, in line 365 , he overlaps and takes the floor. His turn is a continuation of his prior turn (signalled by 'and'), which takes no account of Leah's turn and which skip connects ${ }^{8}$ to his prior talk. This, as Sacks $(1992,349)$ notes, is often used in competition to have the floor. In the continuation of his prior turn, Amit makes a claim to distal deontic authority by telling Leah what to do (line 365-366: you request him to help you with this). In this turn, he upgrades his

8. i.e., he takes a turn which is related to a prior turn, but which is not related to the immediately prior utterance. 
suggestion to a directive, through the use of the imperative form. This, as Stevanovic $(2013,19)$ notes, is a "stereotypical way of issuing orders and commands" which constitutes "a central practice for claiming deontic authority". Moreover, upgrading in this way, as Craven and Potter (2010) demonstrate, is regularly used in cases of non-compliance with requests and its use projects that non-compliance is not an option. However, despite upgrading his suggestion to a directive, this upgrade is also slightly mitigated since he accounts for his order (i.e. line 368-369: because he [Mr Kapoor] is also teaching these classes also) which, as Stevanovic and Peräkylä $(2012,311)$ note, involves a downgrading of the authority claim.

Amit projects a continuation of his turn (line 369: also), but he is overlapped by Leah who orients to Amit's suggestion as redundant (line 370: yeah he has explained me), therefore rejecting his deontic rights to tell her what to do. In the continuation of her turn, she reasserts her deontic rights to manage the finance club by again stating that "I'm just going to convey it further to students" which reaffirms her rights to manage the club and reiterates what she has already decided to do (cf. line 352). Amit, however, overlaps this turn as it is in progress by saying: "I know" (line 373). This displays his K+ status, viz. he already knows that she will inform the students. It is also important to note that whilst displaying $\mathrm{K}+$ status Amit is looking down (see Figure 8), which functions as a contextualization cue (Gumperz 1982, 130) that marks his lack of availability in the participation framework. There is then a slight pause during which Amit keeps on looking down, but he also very briefly shifts his eye gaze halfway up to Leah and back to his papers (see Figures 9 and 10). This quick gaze shift functions as a checking look, rather than an invitation to Leah to take the floor again. Afterwards, Amit looks up again. He first looks to his far left (sharp angle, see Figure 11) and then to his right (wide angle, see Figure 12), thus casting his gaze over a selection of the participants. As Leah is seated at the end of the table, she is outside Amit's gaze and she is thus non-verbally excluded from turn allocation. As such, Amit claims his entitlement to change topic by means of his eye gaze, and he thus allocates the turn to someone else, in this case Riya, who is seated in the corner to Amit's left and who was thus in the centre of his sharp-angled left gaze (see Figure 11). As such, a topic change to the HR club is initiated. Consequently, the issue of seeking, or not seeking, the help of Mr Kapoor is left unresolved and potential conflict over Amit's right to tell Leah what to do, and so his claim to deontic authority, is avoided. Amit thus uses his proximal deontic authority to manage turns as a resource to manage threats to his distal deontic authority and rights to tell others what to do.

In sum, Amit's deontic authority is challenged when Leah fails to align with a course of action that Amit has suggested. As a result of this, Amit upgrades his claim to distal deontic and epistemic authority which reflexively makes his identity 'boss' relevant to the interaction with rights to tell subordinates what to do. 
This is in line with what Taylor $(2012,179)$ suggests: whilst authority is always latently present in institutional interaction, it may often not have to be enforced by hierarchic superiors. As in the beginning of this extract, Amit used a shallow deontic stance to gain compliance without the addressee surrendering her private judgement. However, when this stance is challenged in some way he upgrades his stance and so directly mobilises the 'boss'-identity. Yet, by multimodally displaying topic closure and allocating the next turn to another interlocutor, Amit also avoids explicit conflict with Leah over the resolution of the issue.

\section{Observations}

As Stevanovic (2013, 17-18) notes, "participants' orientation to authority can be perceived, for example, by the degree to which one participant can initiate, maintain, and close up sequences of action, or maintain their version of the ongoing activity". In exercising his right to manage turns, and having this right oriented to by the others, Amit enacts his proximal deontic authority which makes relevant, and is made relevant by, his role-based identity 'chairperson'. However, whilst the relationship between the deontic rights and identity of chair has already been widely commented on (e.g. Stevanovic \& Peräkylä 2014), the novelty of this paper lies in the subtle multimodal ways in which this authority is negotiated. In particular, analyses of eye gaze and gesture reveal how proximal deontic authority in a meeting can be challenged and/or shared in ways that are not clearly visible if the analyses focus solely on sequences of talk. In extracts one and two, both Yash and Ryan putatively claim the right to manage turns through using gesture and gaze rather than talk. Yet, it is Amit's eye gaze that is oriented to as being the non-verbal resource that selects the next speaker, thus confirming his deontic authority to manage turns. So, in these cases, the other participants' claims to share rights to manage turn taking, and so have proximal deontic authority, are not oriented to, and, in the case of Extract (2), Yash's speaker selection is even declined by similar non-verbal resources (viz. Riya's gesture and gaze). Yet, it indicates that by subtle gestures, participants may attempt to manage turn-taking, as such making claims to proximal deontic authority. Thus whilst, as Stevanovic and Peräkylä (2014) argue, in meetings there is a relatively stable asymmetry in deontic rights associated with the identity of chairperson, in this paper we showed that by using multimodal resources (notably gesture and gaze) the chair's deontic authority can be challenged in subtle ways.

The reports of the club's activities are delivered by the faculty members responsible for the clubs. The nomination of the faculty members to speak about the club's activities and the fact that they either open their turns by explicitly stating (extracts 2 and 3 ) that they are responsible for the club, and/or by speaking on behalf of the club (extracts 1 and 2) makes relevant their identities as 
faculty-member-in-charge-of-a-club and mobilises this as a source of authority. Epistemic rights to know are intertwined with distal deontic rights to decide, and when reporting on the clubs the faculty members all use a declarative from. However, these deontic and epistemic rights are negotiated in subtle ways. In Extract (1), in a turn addressed to the director, the faculty member slightly downgrades his epistemic rights to assess the activities by inserting an account. This, thus, hints that deferring to the status based authority of the director could be possible. However, the director produces a second assessment that does not seek to display epistemic primacy, rather it aligns with the faculty member. Thus, the faculty member's epistemic authority in relation to his club is not upstaged. In Extract (2), both the faculty member's deontic and epistemic authority are challenged by a colleague who suggests future action and assesses it. The challenge is only partially successful since by mobilising the club members as a source of authority, the faculty member in charge of the sports club refutes the suggestion and assessment. The faculty member thus does not surrender his own judgment and so resists a colleague's claim to tell him what to do and think. In the final extract, the faculty member in charge of the club claims deontic and epistemic authority based on her identity as person-in-charge of the finance club, but this is challenged by the director. Significant here, is the fact that the director first asserts his deontic rights in relation to the club by formulating a suggestion. It is only when this suggestion is rejected that he upgrades to a directive. Thus, perhaps, one of the key difficulties in analysing authority-in-action is that it becomes most visible only when called into question and when it has to be enforced. Further, it is interesting to note that this challenge to the director's deontic authority is left unresolved because he changes topic and selects a next speaker. Thus, proximal deontic authority can be used to shore up distal deontic authority (and perhaps also epistemic authority) when challenged.

Taken together, the corollary of these observations is that authority:

1. is negotiated on a turn by turn basis and it is accomplished not only through talk, but also by drawing on a variety of - often subtle - non-verbal resources such as eye gaze and hand gestures. Importantly, authority is not something that a person has, rather it is something that is achieved in interaction by making relevant the participants' identity roles as evidenced in the recipient-design of turns.

2. can shift on a turn by turn basis, as is shown by the fact that Tanvi takes a turn asserting her deontic and epistemic authority in relation to the sports club.

3. can be resisted, as Leah does in Extract (3).

4. can be acquiesced to, as Amit's right to open, allocate, and close turns is not once challenged in any of the sequences of talk, even though Yash and Ryan sometimes attempt to co-author turn allocation by drawing on various multimodal resources (hand gestures, eye gaze). 
Taken together, these observations are commensurate with claims by some researchers (e.g., Kahn \& Kram 1994) that in the post-bureaucratic age rational-legal authority is not inherent in a chain of command, rather it is much more negotiable and flexible. However, once authority is resisted as in Extract (3), it is typically upgraded and a chain of command is enforced. Consequently, the analyses also demonstrate that authority is something that, as Taylor and Van Every (2014), Taylor $(2012)$ and Stevanonic $(2013,11)$ argue, becomes most visible when it is threatened in some way.

\section{Conclusion}

Using multimodal CA as a method and drawing on the notions of deontic and epistemic authority, we have argued that deontic rights and epistemic rights are made visible both in sequences of talk and through the use of multimodal resources. The participants use these various resources to make allowable contributions to the interaction according to their role-based identities. Most - though not all ${ }^{9}-$ of these identities (boss, faculty member) are anchored in the structure of the organisation and it is from this that they gain their rational-legal authority and legitimation. Consequently, authority is both a resource for carrying out workplace activities and a consequence of carrying out these activities. As we have demonstrated in this paper, because authority is negotiated in a number of ways, both using multimodal resources and sequences of talk, it is not fixed and so rather than a rigid command and control type organisation (the bureaucratic iron cage), a post-bureaucratic organisation becomes possible in which authority is to some extent dispersed and negotiated.

It is significant that this is also the case in institutional interactions in an Indian context, which is typically regarded as highly hierarchical (Sinha \& Sinha $1990,708)$. On the one hand, the extracts are characterized by a number of visible (e.g. the spatial set-up suggesting a particular hierarchy, see Appendix 2) or superficial markers of hierarchy (e.g. addressing each other with 'sir' or using a honorific marker (e.g. hanji, Extract (3)). Yet, on the other hand, the extracts clearly show that there is also room for challenges by subordinates. In line with research on Western contexts, it is also the case here that most of the time authority does not have to be overtly exercised in institutional interaction and that it typically surfaces after suggestions by superiors are resisted. In such cases, certain participants can upgrade their stance so that the doing of authority becomes visible. This therefore

9. See Tanvi in Extract (3). 
demonstrates that so-called 'cultural' expectations are always generalizations and can never do justice to how interlocutors locally negotiate their epistemic and deontic rights in relation to one another.

Finally, we are aware that the data presented here comes from a small subset of educational settings and that doing authority in other organisations or on other topics may be typified by other, more or less flexible, sequences of talk and use of multimodal resources. However, as Peräkylä $(2011,376)$ observes concerning the validity of fine-grained analyses of naturally-occurring talk, single case qualitative analyses have generalisability because they make visible the seen but unnoticed resources that can be used to 'do' things - such as, in this case, authority - in other similar situations. Nevertheless, in order to have a more nuanced insight into how authority is achieved, we align ourselves with calls by other researchers (e.g. Stevanovic \& Peräkylä 2012; Landmark et al. 2015) for further research to be carried out in other - preferably not uniquely western - contexts. Moreover, we would add that future research could also take a more specifically multimodal approach. In this paper, we specifically aimed to demonstrate the subtle non-verbal ways in which deontic and epistemic authority were negotiated. In particular, we managed to uncover this at the level of proximal deontics (e. g. turn allocation and topic management). However, at the level of distal deontics and epistemics, this still remains fairly elusive (with a few exceptions, for example our discussion of "I know" in Extract (3)). So, in particular, we argue that more research is needed to further uncover the wide variety - and complex intertwining - of verbal and non-verbal resources that can be mobilised by participants in their enactment of authority.

\section{References}

Angouri, Jo, and Meredith Marra. 2010. “Corporate Meetings as Genre: A Study of the Role of the Chair in Corporate Meeting Talk." Text \& Talk 30 (6): 615-636.

https://doi.org/10.1515/text.2010.030

Asmuß, Birte, and Jan Svennevig. 2009. "Meeting Talk: An Introduction.” Journal of Business Communication 46 (1): 3-22. https://doi.org/10.1177/0021943608326761

Barske, Tobias. 2009. "Same Token, Different Actions: A Conversation Analytic Study of Social Roles, Embodied Actions, and ok in German Business Meetings." The Journal of Business Communication 46 (1): 120-149. https://doi.org/10.1177/0021943608325748

Bhatnagar, Jyotsna. 2005. "The Power of Psychological Empowerment as an Antecedent to Organizational Commitment in Indian Managers.” Human Resource Development International 8 (4): 419-433. https://doi.org/10.1080/13678860500356101.

Craven, Alexandra, and Jonathan Potter. 2010. "Directives: Entitlement and Contingency in Action." Discourse Studies 12 (4): 419-442. https://doi.org/10.1177/1461445610370126. 
Deppermann, Arnulf, Reinhold Schmitt, and Lorenza Mondada. 2010. “Agenda and Emergence: Contingent and Planned Activities in a Meeting." Journal of Pragmatics 42 (6): 1700-1718. https://doi.org/10.1016/j.pragma.2009.10.006.

Drew, Paul. 1991. "Asymmetries of Knowledge in Conversational Interactions." In Asymmetries in Dialogue, ed. by Ivana Markova, and Klaus Foppa, 29-48. Hemel Hempstead UK: Harvester.

Gee, James Paul, Glynda Hull, and Colin Lankshear. 1996. The New Work Order. London: Saint Leonards Allen and Unwin.

Goodwin, Charles. 1981. Conversational Organization: Interaction between Speakers and Hearers. New York: Academic Press.

Goodwin, Charles. 2000. "Action and Embodiment within Situated Human Interaction." Journal of Pragmatics 32 (10): 1489-1522. https://doi.org/10.1016/S0378-2166(99)ooo96-X

Griswold, Olga. 2007. "Achieving Authority: Discursive Practices in Russian Girls' Pretend Play." Research on Language and Social Interaction 40 (4): 291-319.

https://doi.org/10.1080/08351810701471286.

Gumperz, John J. 1982. Discourse strategies. Cambridge: Cambridge University Press. https://doi.org/10.1017/CBO9780511611834

Heath, Christian, and Paul Luff. 2013. "Embodied Action and Organizational Activity." In The Handbook of Conversation Analysis, ed. by Jack Sidnell, and Tanya Stivers, 283-307. Chichester: Wiley-Blackwell.

Heritage, John. 2012. "The Epistemic Engine: Sequence Organization and Territories of Knowledge." Research on Language and Social Interaction 45 (1): 30-52. https://doi.org/10.1080/08351813.2012.646685

Heritage, John. 2013. "Epistemics in Conversation." In The Handbook of Conversation Analysis, ed. by Jack Sidnell, and Tanya Stivers, 370-394. Chichester: Wiley-Blackwell.

Jefferson, Gail. 2004. "Glossary of Transcript Symbols with an Introduction.” In Conversation Analysis: Studies from the first generation, ed. by Gene H. Lerner, 13-31. Amsterdam: John Benjamins. https://doi.org/10.1075/pbns.125.02jef

Kahn, William A., and Kathy E. Kram. 1994. "Authority at Work: Internal Models and Their Organizational Consequences.” The Academy of Management Review 19 (1): 17-50. https://doi.org/10.2307/258834.

Kakar, Sudhir. 1971. Authority Patterns and Subordinate Behavior in Indian Organizations. Administrative Science Quarterly 16 (3): 298-307. https://doi.org/10.2307/2391902

Landmark, Anne Marie Dalby, Pål Gulbrandsen, and Jan Svennevig. 2015. "Whose Decision? Negotiating epistemic and deontic rights in Medical Treatment Decisions." Journal of Pragmatics 78: 54-69. https://doi.org/10.1016/j.pragma.2014.11.007.

Larrue, Janine, and Alain Trognon. 1993. "Organization of Turn-taking and Mechanisms for Turn-taking Repairs in a Chaired Meeting”. Journal of Pragmatics 19 (2): 177-196. https://doi.org/10.1016/0378-2166(93)90087-6

Levinson, Stephen C. 1992. "Activity Types and Language." In Talk at work - Interaction in institutional settings (Studies in Interactional Sociolinguistics 8), ed. by Paul Drew, and John Heritage, 66-100. Cambridge: Cambridge University Press.

Lukes, Steven. 1978. "Power and Authority." In A History of Sociological Analysis, ed. by Thomas B. Bottomore, and Robert A. Nisbet, 633-676. London: Heineman.

Mondada, Lorenza. n.d. Conventions for multimodal transcription. Available online at: https:// franz.unibas.ch/fileadmin/franz/user_upload/redaktion/Mondada_conv_multimodality.pdf. Last consulted on 10 January 2018. 
Mondada, Lorenza. 2016. "Challenges of Multimodality: Language and the Body in Social Interaction.” Journal of Sociolinguistics 20 (3): 336-366.

Peräkylä, Anssi. 2011. "Validity in Research on Naturally Occurring Interaction.” In Qualitative Research, ed. by David Silverman, 365-382. London: Sage.

Pomerantz, Anita. 1984. "Giving a Source or Basis: The Practice in Conversation of Telling "how I know'”' Journal of Pragmatics 8 (2): 607-625. https://doi.org/10.1016/0378-2166(84)90002-X Pomerantz, Anita, and Paul Denvir. 2007. "Enacting the institutional role of chairperson in upper management meetings: The interactional realization of provisional authority”. In Interacting and organizing: Analyses of a management meeting, ed. by François Cooren, 31-51. London: Lawrence Erlbaum.

Raymond, Geoffrey. 2000. “The Voice of Authority: The Local Accomplishment of Authoritative Discourse in Live News Broadcasts.” Discourse Studies 2 (3): 354-379.

https://doi.org/10.1177/1461445600002003005

Raymond, Geoffrey, and John Heritage. 2006. “The Epistemics of Social Relations: Owning Grandchildren.” Language in Society 35 (5): 677-705.

https://doi.org/10.1017/So047404506060325.

Sacks, Harvey. 1992. Lectures on Conversation (2 vols, edited by Gail Jefferson with introduction by Emanuel A. Schegloff). Oxford UK \& Cambridge USA: Blackwell.

Sacks, Harvey, Emanuel A. Schegloff, and Gail Jefferson. 1974. "A Simplest Systematics for the Organization of Turn taking for Conversation". Language 50 (4): 696-735.

https://doi.org/10.1353/lan.1974.0010

Sinha, Jai B. P., and D. Sinha. 1990. "Role of Social Values in Indian Organizations." International Journal of Psychology 25 (3-6): 705-714. https://doi.org/10.1080/00207599008247922

Stevanovic, Melisa. 2013. Deontic Rights in Interaction: A Conversation Analytic Study on Authority and Cooperation. Helsinki: University of Helsinki.

Stevanovic, Melisa. 2015. "Displays of Uncertainty and Proximal Deontic Claims: The Case of Proposal Sequences." Journal of Pragmatics 78: 84-97. https://doi.org/10.1016/j.pragma.2014.12.002

Stevanovic, Melisa, and Anssi Peräkylä. 2012. "Deontic Authority in Interaction: The Right to Announce, Propose, and Decide." Research on Language and Social Interaction 45 (3): 297-321. https://doi.org/10.1080/08351813.2012.699260.

Stevanovic, Melisa, and Anssi Peräkylä. 2014. "Three Orders in the Organization of Human Action: On the Interface between Knowledge, Power, and Emotion in Interaction and Social Relations". Language in Society 43 (2): 185-207. https://doi.org/10.1017/So047404514000037

Stevanovic, Melisa, and Jan Svennevig. 2015. Introduction: Epistemics and Deontics in Conversational Directives. Journal of Pragmatics 78: 1-6. https://doi.org/10.1016/j.pragma.2015.01.008

Stivers, Tanja. 2008. "Stance, Alignment, and Affiliation during Storytelling: When Nodding is a Token of Affiliation." Research on Language and Social Interaction 41 (1): 31-57. https://doi.org/10.1080/08351810701691123

Svennevig, Jan. 2012. "The Agenda as Resource for Topic Introduction in Workplace Meetings". Discourse Studies 14 (1): 53-66. https://doi.org/10.1177/1461445611427204

Taylor, Frederick. 1911. Principles of Scientific Management. New York: Harper \& Row.

Taylor, James. 2009. "The Communicative Construction of Community: Authority and Organizing." In Learning and expanding with activity theory, ed. by Annalisa Sannino, Harry Daniels, and Kris D. Gutiérrez, 228-239. Cambridge: Cambridge University Press. https://doi.org/10.1017/CBO9780511809989.015 
Taylor, James. 2012. "L'autorité comme base normative de l'organisation [Authority as a normative base for organisations]." Proceedings of the International Communication Association Regional conference in Europe - Communicating in a world of norms, available at: https:// halshs.archives-ouvertes.fr/hal-00835844v2/document.

Taylor, James, and Elizabeth Van Every. 2014. When Organization Fails. Why Authority Matters. New York: Routledge.

Van De Mieroop, Dorien, and Jonathan Clifton. 2017. "Corporate settings." In The Routledge Handbook of Language in the Workplace, ed. by Bernadette Vine, 127-137. New York: Routledge.

Van De Mieroop, Dorien, and Stephanie Schnurr (eds). 2017. Identity struggles: Evidence from workplaces around the world. Amsterdam: John Benjamins. https://doi.org/10.1075/dapsac.69

Varma, Arup, Ekkirala S. Srinivas, and Linda K. Stroh. 2005. "A Comparative Study of the Impact of Leader-Member Exchange in US and Indian Samples." Cross Cultural Management: An International Journal 12 (1): 84-95. https://doi.org/10.1108/13527600510797971.

Verschueren, Jef. 2008. "Intercultural Communication and the Challenges of Migration." Language and intercultural communication 8 (1): 21-35. https://doi.org/10.2167/laic298.o

Weber, Max. 1978. Economy and Society. Berkeley and Los Angeles: University of California Press.

\section{Appendix 1. Transcription conventions}

The excerpts have been transcribed according to the Jeffersonian transcription conventions. We added the following conventions from Mondada (n.d.) to refine the transcript multimodally:

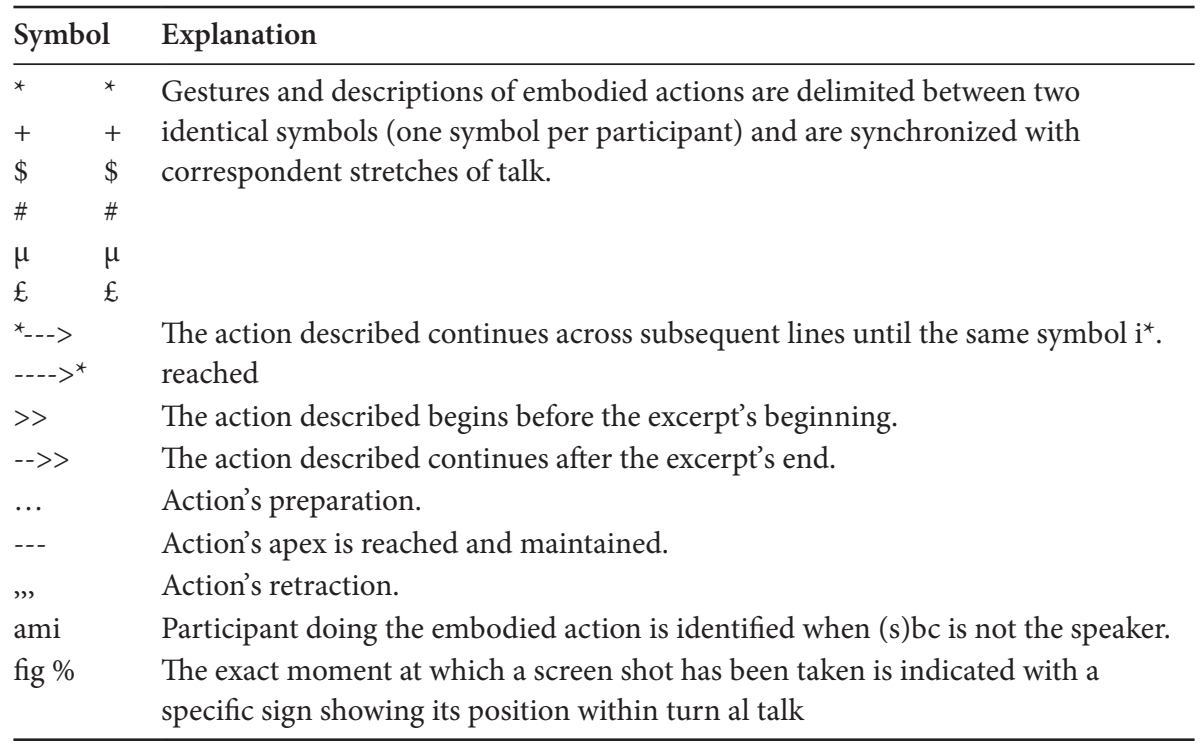




\section{Appendix 2.}

Seating arrangements and pseudonyms of the participants that contribute to the interaction in the extracts presented in this article

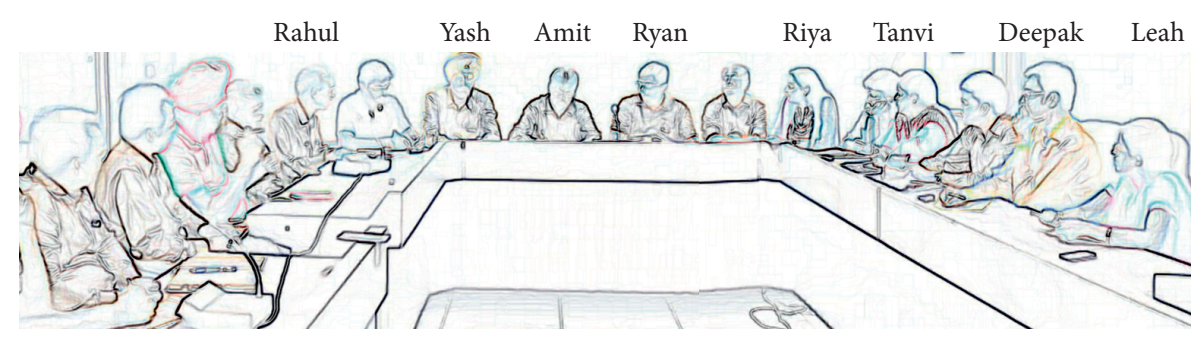

Figure 13.

\section{Authors' addresses}

Jonathan Clifton

Université de Valenciennes

Institut Universitaire de Technologie

Rue des Cent Têtes

Valenciennes 59300

France

Jonathan.Clifton@univ-valenciennes.fr

Dorien Van De Mieroop

KU Leuven

Faculty of Arts

Blijde Inkomststraat 21 bus 3308

Leuven 3000

Belgium

dorien.vandemieroop@kuleuven.be

Prachee Sehgal

(independent scholar)

B-248, Saraswati Vihar

Delhi-110034

India

Prachee.sehgal@gmail.com

Dr. Aneet

I.K.G. Punjab Technical University, Jalandhar

Gian Jyoti Institute of Management \& Technology, Phase -2

Mohali 160055, Punjab

India

aneet@gjimt.com 
